\title{
On Multi-model High-Precision Location Method of Substation Based on CSS Location Technology
}

\author{
Hongyan Yin \\ Beijing Inspection and Quarantine Testing Center of \\ Beijing Entry-Exit Inspection and Quarantine Bureau \\ 100026 China \\ Yujun Liu \\ Beijing Inspection and Quarantine Testing Center of \\ Beijing Entry-Exit Inspection and Quarantine Bureau \\ 100026 China
}

\author{
Tong $\mathrm{Wu}$ \\ China National Institute of Metrology
}

\begin{abstract}
When existing location technologies are applied in substation, there are some deficiencies. In the paper, a multimodel high-precision location method is proposed based on CSS location technology. Firstly, it analyzes several mainstream location technology and the characteristics of substation. Secondly, it introduces the location process and hardware implementation based on the combination CSS location with region fingerprint location. Lastly, the feasibility of this method is verified by the real test in a smart substation.
\end{abstract}

Keywords-location technology; CSS; location of substation

\section{INTRODUCTION}

With the improvement of substation automation and the rapid development of location technology, the substation's demands for personnel and goods precise location are becoming more and more urgent. Presently, there aren't effectively regulated systems for station staff and instruments in most domestic substation, which usually causes that staffs leave, accidents cannot be rescued timely, and tools are difficultly found or are lost. The real-time precise location technology cannot only patrol tracking and monitor behavior of staff, which can realize effective administration for staff and accident warning, investigate the guard situation of inspectors, and prevent violations etc.,but also can effectively manage instruments of substation, which can solve the problem that substation's instruments depend on handicraft admin istration, even realize rapidly location of instruments. Therefore, it provides instruments administration of substation with an automated monitor method. It also can improve the efficiency. But above all, it is necessary that using advanced location technology to realize real-time precise location for substation staffs and items.

\section{THE ANALYSIS AND SELECTION OF LOCATION TECHNOLOGY FOR SUBSTATION}

\section{A. The Compare Analysis of Location Technology}

Presently, location technology is more and more noticeable for mark demands. Domestic and foreign institutions conduct lots of studies, so many advanced location technologies are proposed. According to the difference between indoor and outdoor location environment, it is divided into two categories: indoor location technology and outdoor location technology. Outdoor location technologies are mainly GPS and basestation etc. GPS is a mature wireless location technology for outdoor environment, and it has been widely applied in many industries. Base-station location is generally applied in mobile phone location, and its error is bigger. Those location technologies cannot be applied in indoor environment, because they cannot provide precise location. But the demands of indoor location are more, because people act frequently. Therefore, many indoor location technologies are proposed, such as $\mathrm{WiFi}$, bluetooth, ultra wide band(UWB), chirp spread spectrum(CSS), radio frequency identification(RFID) technology, wireless sensor network(WSN) location technology(represented by ZigBee), infrared and ultrasonic location technology etc, as shown in Fig. 1.

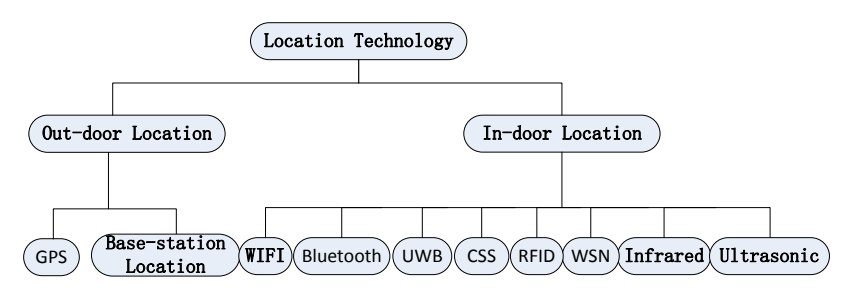

Figure 1. The classification of location technology

Infrared and ultrasonic location technologies aren't popularized in application, because they are complex and expensive. But products based on RFID will be applied widely for their precise location, relatively low prices and easy deployment. The characters of these location technologies are shown in Table 1. There is a close relation between location precision and system deployment or coverage region. The precision in Table 1 is the value that general application can be able to achieve. 
TABLE I. COMPARISON OF SEVERAL MAIN LOCATION TECHNOLOGIES

\begin{tabular}{|c|c|c|c|c|c|c|}
\hline $\begin{array}{l}\text { Location } \\
\text { Technology }\end{array}$ & $\begin{array}{l}\text { Location } \\
\text { Precision }\end{array}$ & Cost & Power & $\begin{array}{l}\text { Coverage } \\
\text { range }\end{array}$ & Advantage & Disadvantage \\
\hline GPS & & higher & high & wide & $\begin{array}{l}\text { Mature } \\
\text { technology and } \\
\text { wide application }\end{array}$ & $\begin{array}{l}\text { It isn't suitable for many barriers } \\
\text { or indoor location. }\end{array}$ \\
\hline WIFI & & high & high & & $\begin{array}{l}\text { Easy installation } \\
\text { and simple layout }\end{array}$ & High cost and bad stability \\
\hline Bluetooth & $2 \sim 10 \mathrm{~m}$ & higher & low & & $\begin{array}{l}\text { Low power and } \\
\text { easy integration }\end{array}$ & $\begin{array}{l}\text { Short distance, bad stability and } \\
\text { it is vulnerable to noise } \\
\text { interference. }\end{array}$ \\
\hline UWB & & high & low & & $\begin{array}{l}\text { High precision } \\
\text { and low power }\end{array}$ & High cost \\
\hline CSS & & low & low & (scalability) & $\begin{array}{l}\text { High precision } \\
\text { and low cost }\end{array}$ & $\begin{array}{l}\text { High requirement of hardware } \\
\text { performance }\end{array}$ \\
\hline RFID & & low & low & & $\begin{array}{l}\text { Low cost and } \\
\text { small size }\end{array}$ & $\begin{array}{l}\text { Short distance, it can } \\
\text { communicate and isn't convenient } \\
\text { to integrated with others. }\end{array}$ \\
\hline ZigBee & & low & low & & $\begin{array}{l}\text { Low power and } \\
\text { low cost }\end{array}$ & $\begin{array}{l}\text { Bad stability and bad stability, it } \\
\text { is vulnerable to noise interference. }\end{array}$ \\
\hline
\end{tabular}

\section{B. Selection of Location Technology for Substation}

Comparing with general location applications, substation location has the following technology difficulties for specificities of environment:

1) Complex application environment: There are many barriers of signal transmission in substation location environment, such as wall, electrical equipments and cables. Because the position and distribution of barriers are different, it causes the complex wireless signal transmission environment. Therefore, it is difficult to sequentially acquire location signal, and it is easy to form location islet phenomenon.

2) Many interference sources: Because substation environment is relatively closed, the interference sources (such as electromagnetic field, light and temperature) can effect on sensors of location equipments. The change of wireless signal strength isn't obviously corresponding with position. So the location method based on receive signal indication cannot guarantee precision.

3) Strict location deployment and cost requirement: In order to guarantee substation safe and reliable operation, location system should be simple and the cost should be strictly limited.

4) Complexity and diversification of location application: Substation location technology is mainly applied in precise locating for staff and items. Its characters are multiple location body simultaneous location, mobile location and real-time tracking trajectory. All of these put forward high requirements for location system's power, precision, real-time, continuity, stability and integration.

Through the above analysis, the location technologies proposed in this paper are used for substation location, but there are some problems. On the one hand, low precision cannot correctly judge the precise position of staffs and items, then causes error. On the other hand, it cannot be widely applied for high cost. Therefore, aiming at substation application environment, a low-cost highprecision location method based on CSS location technology and using substation existing communication network and equipment to locate is proposed in this paper.

\section{MULTI-MODE HIGH-PRECISION LOCATION METHOD BASED ON CSS TECHNOLOGY}

With the development of smart substation, wireless communication technology is applied in substation automation system and popularized. WSN and $\mathrm{WiFi}$ technologies (such as WIA, ZigBee) have made some smart substation online-monitor and subsidiary controlling systems realize all wire less structure. These applications of wireless communication will provide available help for substation location technology.

\section{A. The Introduction of CSS Location Technology}

CSS is a wireless communication technology based on IEEE802.15.4a protocol. It adopts pulse compression processing, and makes received pulse easily detected since 
it is concentrated. It can acquire spike pulse compressed output after processing with matched filter in receiver. So it can correctly obtain the time of signal arriving in receiver. CSS location technology generally adopts SDSTWR measurement method based on TOA to acquire the time of two-way transmission. Then it can acquire the distance of node, and the measurement principle is shown in Fig. 2. Firstly, tag transmits test signal to base-station and timer starts. After base-station receiving test signal, its own timer starts. Meanwhile hardware automatically returns an answering signal, and timer is stopped. Secondly, it reads disposing delay T1. After tag receiving hardware answering signal, timer is stopped and it reads signal round trip delay $\mathrm{T} 2$. Lastly, beginning with basestation trans mitting test signal, above measurement process is repeated once. Tag reads disposing delay $\mathrm{T} 3$ and basestation reads signal round trip delay $\mathrm{T} 4$.

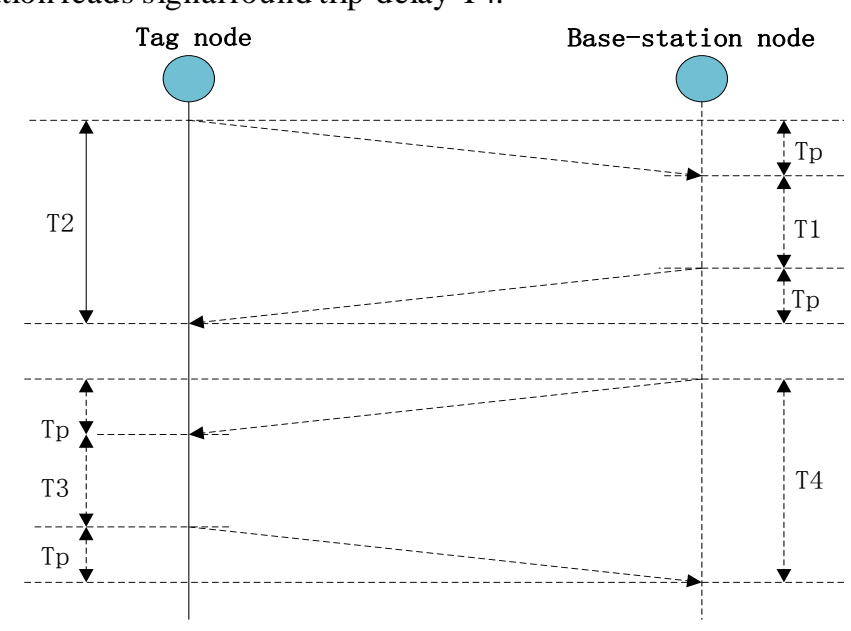

Figure 2. Flow diagram of SDS-TWR measurement

In above measurement process, tag and base-station conduct twice symmetrical measurement processes. Each includes once signal round trip time, so it can obtain transfer time between tag and base-station:

When velocity of light is expressed as c, the distance between tag and base-station is shown following:

SDS-TWR measurement doesn't need time synchronization between tag and base-station. Therefore, it is simple to realize the system, and it can efficiently reduce measuring error caused by hardware clock frequency deviation.

The advantages of CSS location technology are better capacity of resisting disturbance, high multipath resolving power, small frequency deviation influence, low power dissipation and little cost. So CSS is more suitable for substation application than other location technologies.

\section{B. Multi-mode fusion location}

Although CSS has more advantages than other location technology in substation application, only using CSS location technology based on time measure has more error in non-line of sight (NLOS) propagation areas for complex substation environment and more barriers. Even because of serious overlap, the positions of more than three basestations cannot be acquired. However, it cannot be located by trilateral method, even appears the phenomenon of location is let.
The deployment of WSN and WiFi node is invariable in substation, and it usually is distributed near electrical equipments. When the effect of CSS location is undesirable, WSN or WiFi nodes is intensive. It can make up the deficiency of CSS location by using micro-region position fingerprint location technology. At the same time, it can guarantee location precision and continuity.

Substation multi-mode fusion location methods based on CSS are divided into off-line and on-line training phase.

1) Off-line training phase

It is different from the off-line training of tradition fingerprint location. The method proposed in this paper has two steps. In the first step, substation location regions are divided by CSS location technology. In the second step, position fingerprint collection is conducted in divided regions, and the detail process is shown in Fig. 3:

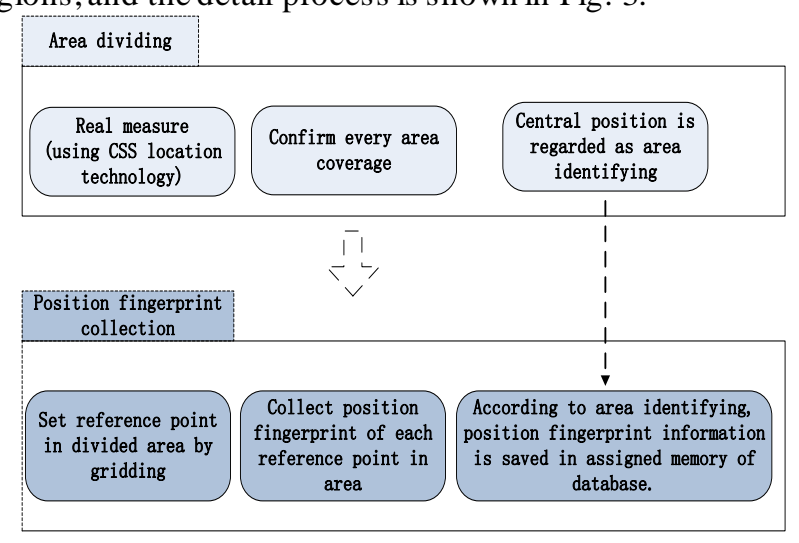

Figure 3. Flow diagram of out-line training

a) Dividing regions: Firstly, according to floor space of substation, location precision or demand of cost and deployment, CSS location base-station is installed. Secondly filed measurement is conducted by CSS location technology. Generally, most of substation regions can be located directly. But it cannot realize ideal result in some small regions with intensive barrier. Therefore, according to substation environment and distribution of important movement areas, it conducts the preliminary range partition. It also can enhance work efficiency of range partition. However, when area of substation is small or requirement of work strength is low, it should realize whole region measurement and diminish located blind region. Comparing measurement with real position, the position will be recorded when error is above limit-value or measurement cannot be conducted (or can't acquire more than three base-station). Then it frequently measures near the region by the same method. Lastly it can obtain final range of this region. Central position should be regarded as identifying of this location region and be saved after confirming region range.

b) Position fingerprint collection: Location region divided is segmented into equidistant grid. There is a reference point in every intersection of grid. Signal strength of WSN or WiFi node is collected near every reference point. After repeat collection of a reference point, all of these values are averaged and the obviously fluctuated signal is eliminated. Then it can compose a 
vector $\left\{\mathrm{SS}_{\mathrm{i}}{ }^{1}, \mathrm{SS}_{\mathrm{i}}{ }^{2}, \ldots, \mathrm{SS}_{\mathrm{i}}{ }^{\mathrm{N}}, \mathrm{SF}_{\mathrm{i}}{ }^{1}, \mathrm{SF}_{\mathrm{i}}{ }^{2}, \ldots, \mathrm{SF}_{\mathrm{i}}{ }^{\mathrm{M}}\right\}$, where SS or SF is signal strength of WSN or WiFi node, $i$ is ith reference point, and N or M is the number of WSN or WiFi nodes searched in region. Position information of this point as a fingerprint is saved in position fingerprint database. Every location region has itself storage area corresponding to area identifying in position fingerprint database. Scene of off-line training phase is shown in Fig. 4.

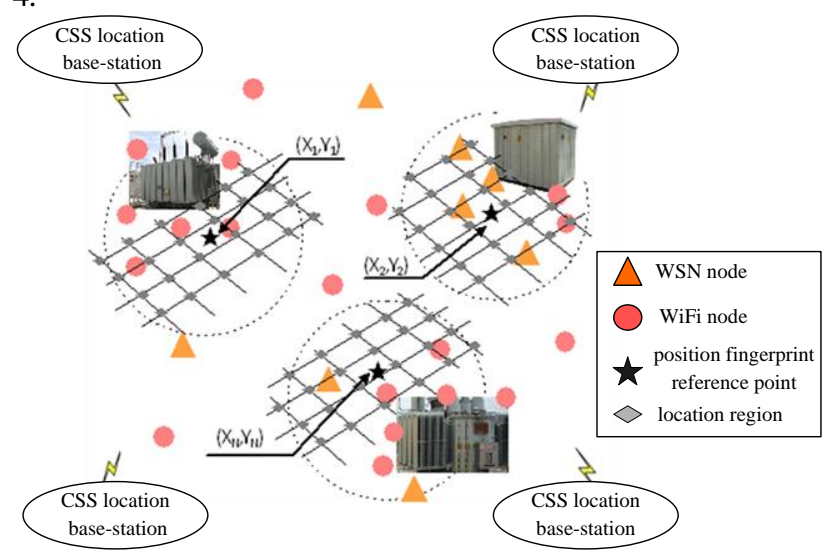

Figure 4. Scene of off-line training phase

\section{c) On-line location phase}

It uses a method that combines CSS location with area position fingerprint location to achieve precise location of object in on-line location phase. The specific realization process is shown in Fig. 5:

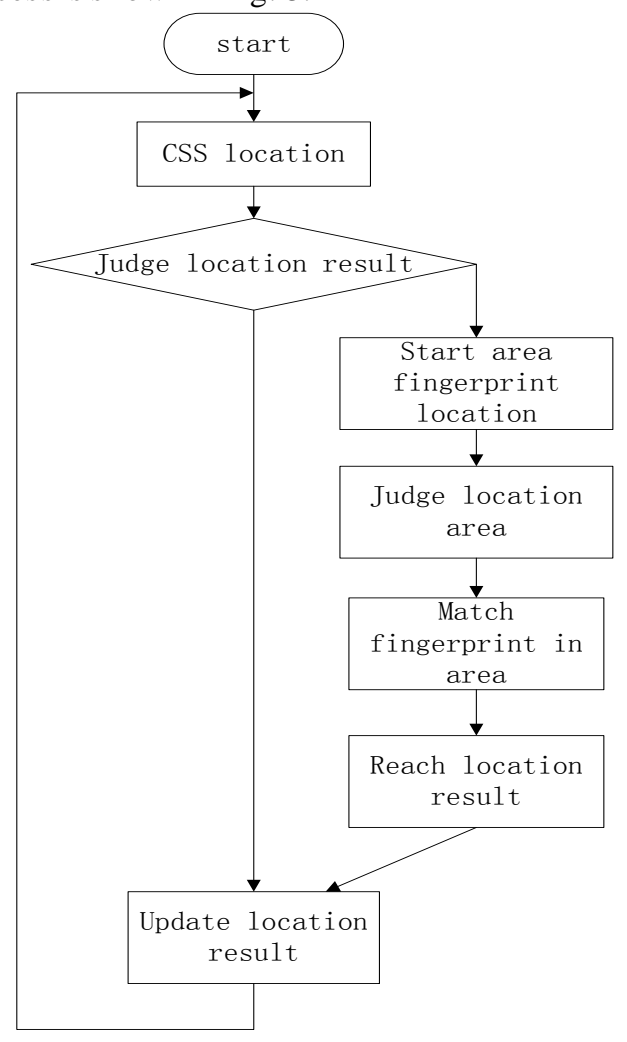

Figure 5. Flow diagram of on-line location

Firstly it uses CSS location technology to measure target position after location process. When measure result is abnormal, area position fingerprint location begins. The judgment of abnormal measure result is as follows:

1) Measure cannot be finished, or it cannot search more than three CSS location base-station signal;

2) There is a big difference between adjoin twice measure results, as the following:

Where is Euclidean distance between adjoin twice measure results in $(1),(x, y)$ is coordinates of measure position, (xp, yp) is last measure result, and is judgment threshold that can be estimated by the speed of present measure, location time interval and location precision.

In order to guarantee location precision and diminish judgment error in CSS location process, it can confirm the result by calculating average of many measure values. It should maximize the number of measurements in the case of meeting real-time requirement. The time of once CSS location measure is several milliseconds. It can satisfy most location application situations.

After opening area position fingerprint location process, it firstly needs to judge affiliated area according to current position. Similarly, it calculates the Euclidean distance between current position and the center of each location area. When distance is the smallest, the position is belonged to the area. Then it can calculate the target position in the area by fingerprint matching.

\section{HARDWARE IMPLEMENTATION}

The embedded location module is an entity of above location methods. It can be integrated with handheld or wearable device, safety instrument and inspecting robot to achieve precise location of substation staff and items.

The embedded location module is consisted of location engine, CSS distance measure module, WSN and WiFi signal collecting module, location fingerprint database, power module and communication interface. It is shown in Fig. 6.

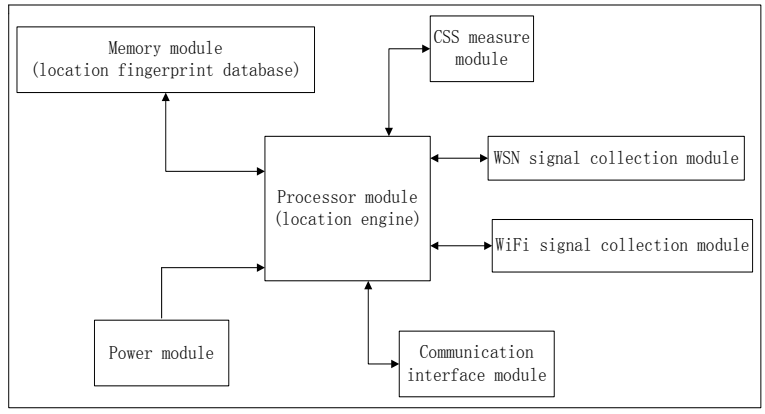

Figure 6. Composition of embedded location module

The kernel of embedded location module is location engine. Through comprehensive analysis of CSS distance measure module with WSN and WiFi signal collecting module, it can divide area in out-line training phase, and also can establish position fingerprint database. Even it can switch location mode in on-line location phase and get target position.

Location fingerprint database is saved in memory module, and it includes divided area identifying and signal strength fingerprint information of multi-reference point in corresponding area. Module adopts advanced power management plan in power design. It sufficiently considers the balance between property and power. In the case of meeting property requirement and guaranteeing user well 
experience, it should reduce the overall power of terminal device. It adopts integrated and modularized design in physical design. Through normal communication interface (UART, SPI and I2C), it is convenient to be integrated in various devices. Module entity is shown in Fig. 7.

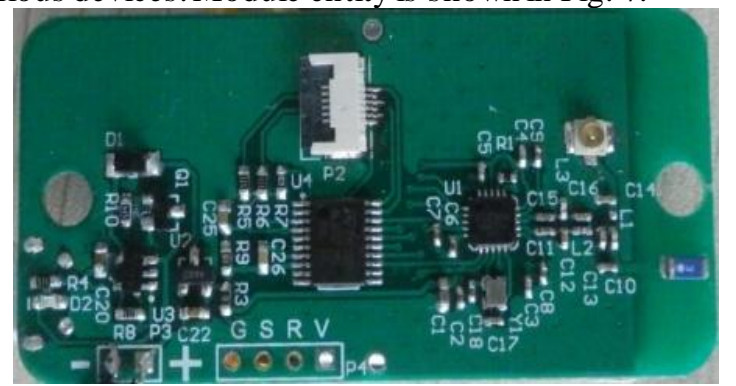

Figure 7. Entity of embedded location module

\section{APPLICATION TEST}

In order to verify the proposed method in this paper, application test is conducted in a $220 \mathrm{KV}$ smart substation. The on-line monitoring system of this substation adopts whole wireless structure, which is shown in Fig. 8. The system is divided into three layers. Process layer adopts WIA industrial wireless sensor network (WSN) communication. It monitors the situation of HGIS switchgear and transformer. However the monitoring data is transmitted to integrated monitoring unit of wall layer. Integrated monitoring unit communicates with master station upward through WiFi network.

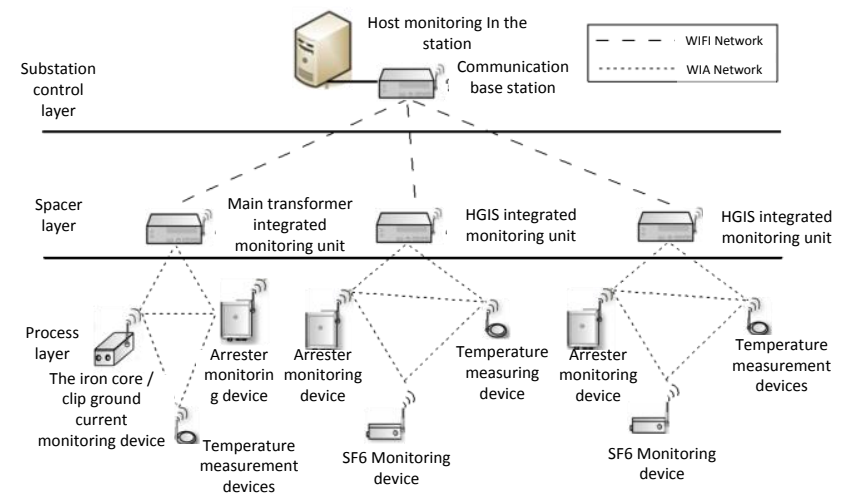

Figure 8. The diagram of all-wireless substation line monitoring system

The substation is a highly integrated substation. It is 180 meters by 120 meters. It is mainly divided into HGIS spacer region consisted of HGIS switchgear and master transfer region consisted of transformer device. Optimum application range of CSS location technology is $5 \sim 50 \mathrm{~m}$. With the comprehensive consideration of cost and the difficulty of base-station deployment, it decides to deploy 14 CSS location base-station in substation. The deployment result is shown in Fig. 9.

It can conduct out-line training after establishing basestation. Firstly, experimenters who have mobile terminal with embodied location module measure along planned traversal path in substation. The limited error is 3 meters during measurement. It real-timely records failed location and transfinite error position, and the measurement result is shown in Fig. 9. It is obvious that non-ideal location region is mainly focused on HGIS area near master transfer region and spacer region.

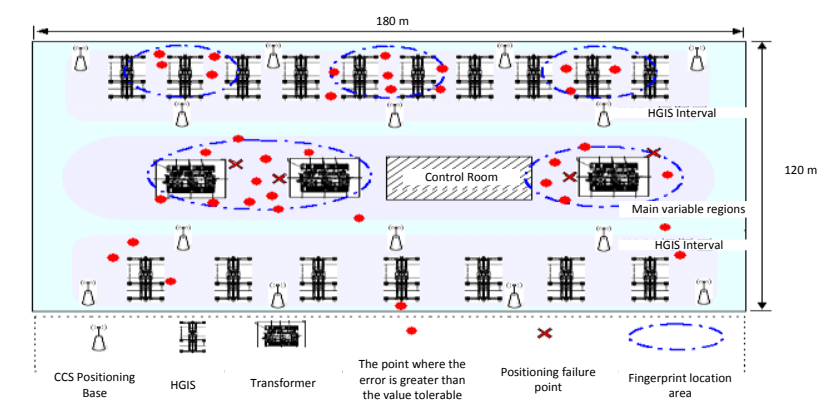

Figure 9. The regional division of substation locating

When collecting location fingerprint, the number of reference points can slightly effect on location matching delay for little area of divided area. Therefore, according to real situation, it should set reference points as more as possible to improve location precision. It sets a fingerprint reference point every 1 meter in this application. After outline training, location results should be verified in representative master transfer region or near. Because staff movement speed and measure interval have little effect on judgment threshold during testing, it can be ignored. So is equal to limited value 3 meters. Through analys is for most collecting data, it is the distribution of location error accumulation as shown in Fig. 10.

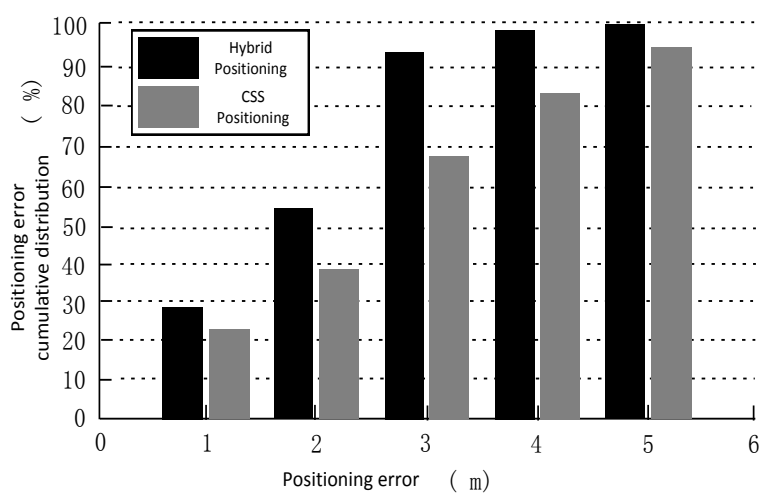

Figure 10. The comparison display of positioning error

It is that $90 \%$ location error can be controlled in 3 meters and maximum error is not more than 5 meters by combining CSS location with fingerprint. However error below 3 meters is less than $70 \%$, and error fluctuation range is bigger only by CSS location. It is obvious that the method that combines CSS location with fingerprint location can efficiently decrease the location error of CSS location. So it can enhance whole location precision and stability.

Through the real testing, it is that the precision of fingerprint location is higher than CSS in some undivided regions. Therefore, if situation is possible, fingerprint location area can be properly enlarged by comparing the precision of CSS location with fingerprint. The location precision can be improved continually. 


\section{CONCLUSIONS}

Multi-mode location method based on CSS includes wireless sensor network and WiFi network in substation. What's more, it combines CSS location with area position fingerprint location. With low cost and simple deployment, it can real-time continuously and preciously locate for staff and items in substation. It also can promote informatization, automation and interaction of substation monitoring. Therefore it can provide powerful condition to smart substation establishment.

\section{ACKNOWLEDGEMENT}

This work is supported by the national quality inspection service project under Grant 201410050.

When implementation of the systems, the signals from the transmission on-line monitoring communication system are pre-processed with the "Smart Signal Processing" software developed by Prof. Ming-Yue ZHAI from North China Electric Power University.

\section{REFERENCES}

[1] Hyeonwoo Cho, and Sang Woo Kim, 2010, Mobile Robot Localization Using Biased on Chirp-Spread-Spectrum Ranging: IEEE Transactions on industrial electronics, 57(8): 2826-2835.

[2] Stan E. Dosso, Gary H. Brooke, Steven J. Kilist off, and Barbara J. Sotirim, High-precision array element localization for vertical line arrays in the Arctic Ocean: 1998, IEEE Journal of Oceanic Engineering, 23(4): 365-379.

[3] Goldie Nejat, and Beno Benhabib, 2006, Line-of-sight task-space sensing methodology for the localization of robotic end-effectors: IEEE/ASME Transactions on Mechatronics, 11(2): 225-232.

[4] Huijuan Hou, Gehao Sheng, and Xiuchen Jiang, Localization Algorithm for the PD Source in Substation Based on L-Shaped Antenna Array Signal Processing:2014, IEEE Transactions on Power Delivery: 1-11.

[5] YANG Zhengwen, the Research and Implementation of highprecision indoor position based on CSS technology [D], Hunan University, 2013.

[6] Li Fang, Research on Indoor position Technology of Location Fingerprint Method Based on ZigBee[D], Harbin Institute of Technology,2012. 